\title{
Prevalence of antibody to Brucella species in butchers, slaughterers and others
}

\author{
A. Karimi, ' A. Alborzi, ' M. Rasooli, 'M.R. Kadivar, ${ }^{\dagger}$ and A.R. Nateghian'

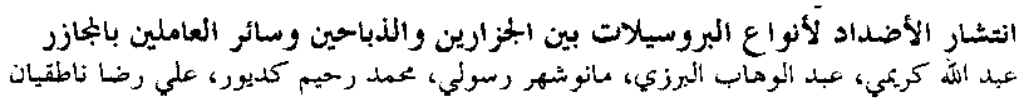

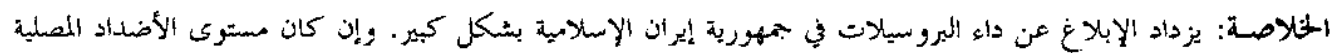

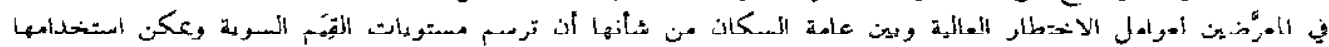

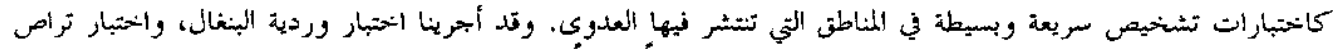

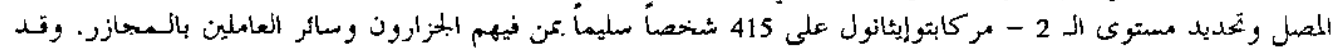

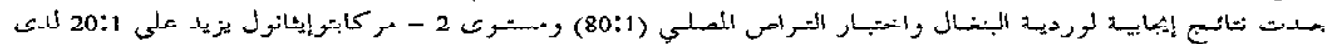

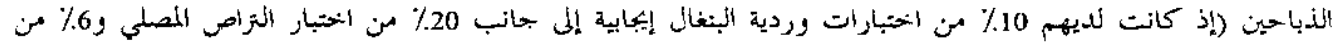

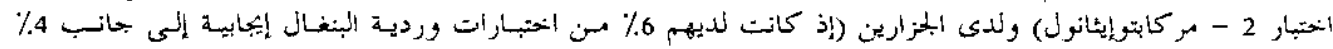

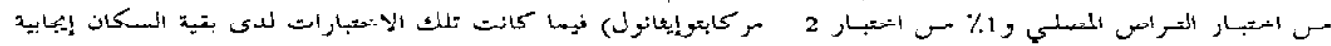

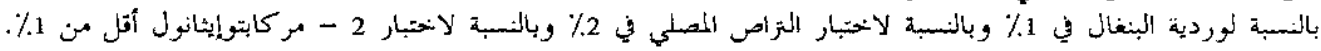

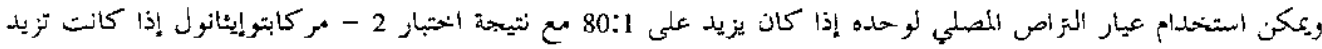

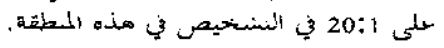

ABSTRACT Brucellosis is being reported with increasing frequency in the Islamic Republic of Iran. Serum antibodies in high-risk and general populations help to define cut-off levels and can be used as a simple and rapid diagnostic tests in infected areas. We performed the rose Bengal test (RBT), serum agglutination test (SAT) and 2-mercaptoethanol (2ME) titre determination on 415 healthy individuals including butchers, slaughterers and others. Positive results were found by RBT, SAT titre $(1: 80)$ and $2 \mathrm{ME}$ titre $\geq 1: 20$ in slaughterers $(10 \%, 20 \%$ and $6 \%$ respectively), butchers $(6 \%, 4 \%$ and $1 \%$ respectively) and the general population ( $1 \%, 2 \%$ and $<1 \%$ respectively). A single SAT titre $\geq 1: 80$ in the presence of $2 \mathrm{ME}$ titre $\geq 1: 20$ can be diagnostic in this region.

Prévalence des anticorps contre les espèces de Brucellachez les bouchers, les abatteurs et dans la population générale

RESUME La brucellose est actuellement signalée de plus en plus fréquemment en République islamique d'Iran. Les anticorps sériques dans les groupes à haut risque et la population générale aident à définir des niveaux seuil et peuvent être utilisés comme tests diagnostiques simples et rapides dans les zones infectées. Nous avons réalisé l'épreuve au rose Bengal, le test de séroagglutination et le titrage par le test au mercapto-2-éthanol chez 415 sujets sains comprenant des bouchers, des abatteurs et d'autres personnes choisies dans la population générale. Des résultats positifs ont été trouvés par l'épreuve au rose Bengal, le titre du test de séroagglutination (1:80) et le titre mercapto-2-éthanol (supérieur ou égal à 1:20) chez les abatteurs $(10 \%, 20 \%$ at $6 \%$ respectivement), les bouchers ( $0 \%, 4 \%$ et $1 \%$ respectiverrieril) el dans la population générale ( $1 \%, 2 \%$ et $<1 \%$ respectivement). Un seul titre pour le test de séroagglutination supérieur ou égal à 1:80 en présence d'un titre mercapto-2-éthanol supérieur ou égal à 1:20 peut constituer un diagnostic dans catte région.

'Professor Alborzi Clinical Microbiology Research Centre (PACMRC), Shiraz University of Medical Sciences, Shiraz, islamic Republic of iran.

Received: 24/01/02; accepled: $14 / 05 / 02$ 


\section{Introduction}

Brucellosis is an important public problem in many developing countries. The disease is found globally, but is more common in the Mediterranean basin, the Arabian Peninsula, the Indian subcontinent and in parts of Mexico and Central and South America [1]. In the Islamic Republic of Iran, brucellosis represents a major health problem and continues to be reported with increasing frequency from various parts of the country [2]. Incidence of brucellosis in Fars province in the southern part of the country is considered low in comparison with other heavily infected provinces. However, according to data derived from active surveillance during 1998. the incidence was about 34 per 100000 people [3]. According to that active case finding, approximately $30 \%$ of cases were among farmers. slaughterers and butchers or had an occupational risk factor [3]. Furthermore, one large study from 1986 disclosed that approximately $7.4 \%$ of cows were infected [2]. As $83 \%$ of cases in the country are in individuals less than 40 years old [2], the importance of occupational exposure especially during adolescence and young adulthood can not be overemphasized [4].

Diagnosis is confounded largely because of a non-specific clinical picture, so diagnosis is only made with certainty when Brucella species are recovered from blood, bone marrow or other sites $[1,4]$. Although most laboratories now employ rapid isolation techniques (BACTEC, Dupont isolator, polymerase chain reaction methods and so on), these techniques are not available in most developing countries and conventional methods of isolation are too slow to use routinely for diagnosis $[1,4-6\rceil$. Therefore, in the absence of bacteriologic confirmation, a presumptive diagnosis can be made on the basis of a single high or rising titre of
Sperific antibodies $[1,4]$. A variety of serologic 1 tests has been applied to brucellosis, of which serum agglutination test (SAT) is the most widely used [ $6-8]$. Evaluation of various enzyme-linked immunosorbent assays (ELISA) for IgG and IgM has shown that these techniques are generally more sensitive and specific than conventional tests $[7,9]$, but these techniques are also not generally available for routine use in developing countries, especially in rural ateas. Hence, every effort is needed to increase the sensitivity of available tests.

As the serum level of antibodies in highrisk and general populations were examined in our study, serum levels were investigated in order to avoid reducing the sensitivity of the SAT through the routine application of a predetermined titre (i.e. $\geq 1: 160$ ) [9] and because no single titre of Brucella spp. antibodies is always 'diagnostic' [ 1$]$. This enabled us to define a cut-off level that can be used as a simple and rapid diagnostic test in infected areas [8]. The results also indicated that sex and educational level must be considered when deciding upon a single SAT titre in a region.

\section{Methods}

In this cross-sectional study, the rate of Brucella spp. seropositivity was investigated from October 1999 to August 2000 in Shiraz, Islamic Republic of Iran. The study population consisted of 3 groups: 120 butchers, 130 slaughterers and 264 males and females from the general population. The butchers and slaughterers were approached at their workplaces and after a brief discussion about the aims of the study voluntarily agreed to participate. The others were selected at various laboratory centres after checking that they had been referred by their physicians for routine check-ups.

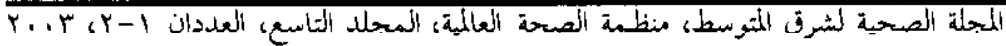


Those individuals with previous history of brucellosis or compatible signs or symptoms such as night sweating, prolonged fever, fatigue, anorexia, weight loss, headache or arthralgia at any time during the preceding two years were excluded. Also, after physical examination, those individuals with positive evidence of lymphadenopathy, hepatomegaly or splenomegaly were excluded from the study. As a result, 99 individuals including 20 butchers and 25 slaughterers were either excluded or chose not to participate.

A total of 415 asymptomatic individuals participated in this study (100 women and 110 men from the general population, 105 slaughterers and 100 butchers). Each completed a questionnaire in which data about sex, age, education, job, consumption of unpasteurized dairy products or raw meat, direct contact with domestic animals or handling of parturient domestics or placental membranes were recorded. General knowledge regarding the route of transmission of the disease and was also questioned. For each case, a blood sample was obtained by venepuncture and all samples were analysed by the rose Bengal test (RBT), SAT and 2-mercaptoethanol (2ME) titres. To avoid laboratory error from the prozone phenomenon, SAT was tested routinely up to $1: 1280$.

Chi-squared and Fisher exact tests were used as statistical methods in order to determine the correlation of epidemiological variables with serologic tests.

\section{Results}

The RBTs used for all three groups were positive for $10 \%$ of slaughterers, $6 \%$ of butchers and $1 \%$ of the general population. Overall, $4.3 \%$ of all participants were positive, with varying degrees of positivity.
However, a greater degree of positivity $(+3$ and +4 ) was found only in high-risk groups, i.e. slaughterers and butchers. There were another 8 sera $(2.2 \%$ of all cases) that had negative results with RBT but positive SAT titres $(\geq 1: 80$ ) and $1 \%$ with positive $2 \mathrm{ME}$ titres $\geq 1: 20$. Furthermore, in $25 \%$ of cases SAT titres were less than 1:80 despite positive RBTs. SAT determination in the three groups were positive $(1: 80)$ for $20 \%$ of slaughterers, $4 \%$ of butchers and $2.4 \%$ of the general population ( $2 \%$ of women and $3.6 \%$ of men). No higher titre was found in the general population but lower titres were found frequently; positive SAT titre of 1:40 was found in $45 \%$ of slaughterers, $32 \%$ of butchers and $38 \%$ of the general population. Although low titres of the $2 \mathrm{ME}$ test were frequent, it was found that a positive $2 \mathrm{ME}$ titre $\geq 1: 20$ was significantly more prevalent in high-risk groups $(P<0.05)$, i.e. $6 \%$ of slaughterers, $1 \%$ of butchers and less than $1 \%$ of the general population (Table 1).

Among the general population there was a clear trend of increasing rate of seropositivity with increasing age that was most marked between the 2nd and 5th decades of life. There was also a strong correlation between occupational status and positive SAT titre $\geq 1: 80(P=0.001)$. Illiteracy and ignorance of routes of transmission were significantly correlated with the rate of scropositivity by $2 \mathrm{ME}$ (with any titre) and SAT titre $\geq 1: 80(P=0.025$ and $P=0.016$ respectively). Frequency of other risk factors and their association with SAT titres is summarized in Table 2.

\section{Discussion}

Recreational and occupational exposure to Brucella spp. has been recognized as an important risk factor even in areas in which 
Table 1 Frequency of positive RBT, SAT and $2 \mathrm{ME}$ titres within study groups

\begin{tabular}{|c|c|c|c|c|c|}
\hline Group & Total no. & $\begin{array}{l}\text { Positive } \\
\text { RBT }(\%)\end{array}$ & $\begin{array}{c}\text { SAT titre Z } \\
\text { 1:80 (\%) }\end{array}$ & $\begin{array}{c}\text { SAT titre }= \\
1: 40(\%)\end{array}$ & $\begin{array}{c}2 M E \text { titre } 2 \\
1: 20(\%)\end{array}$ \\
\hline Slaughterers & 105 & 10 & 20 & 45 & 6 \\
\hline Butchers & 100 & 6 & 4 & 32 & 1 \\
\hline General population & 210 & $<1$ & 2 & 38 & $<1$ \\
\hline
\end{tabular}

RBT = rose Bengal test.

$S A T=$ serum agglutination test.

$2 M E=2$-mercaptoethanol.

brucellosis has been disappearing $[8,10-$ 12]. Therefore, a screening or diagnostic test can be considered reliable only after assessing the individual's risk factors. In this study RBI had an acceptable sensitivity as a screening test especially for the general population [6]. Its specificity, however, was unacceptable in cases with previous occupational exposure; therefore, RBT should be followed by other more reliable diagnostic tests for such cases. It was also found that greater intensity of results in RBTs (i.e. +3 and +4 ) was found only in high-risk groups, so in the absence of these risk factors such results should be followed more seriously.

This study also showed positive SAT titre equal to $1: 80$ in $20 \%$ of slaughterers, $4 \%$ of butchers and $2.4 \%$ of the general population. There was a significant difference in the incidence of seropositivity to Brucella spp. between men and women. Overall, SAT titre $\geq 1: 80$ could be used as a cut-off point in the general population in this region. Furthermore, significant $2 \mathrm{ME}$ titres (i.e. $\geq 1: 20$ ) were positive in less than

\begin{tabular}{lcccc}
\hline $\begin{array}{l}\text { Table } 2 \text { Risk factors investigated and their association with SAT } \\
\text { titres (total cases = 415) }\end{array}$ & Total no. & $\begin{array}{c}\text { SAT titre }=1: 80 \\
\text { No. +ve sera } \\
\%\end{array}$ & $\begin{array}{c}\text { Correlation after } \\
\text { statistical } \\
\text { analysis }\end{array}$ \\
\hline Risk factor & 239 & 22 & 9 & No \\
\hline $\begin{array}{l}\text { Drinking raw milk } \\
\text { Eating raw meat }\end{array}$ & 152 & 15 & 10 & No \\
$\begin{array}{l}\text { Close contact with } \\
\text { domestic animals }\end{array}$ & 169 & 20 & 12 & No \\
$\begin{array}{c}\text { Handling parturient } \\
\text { domestic animals }\end{array}$ & 69 & 7 & 10 & No \\
$\begin{array}{c}\text { Contact with placental } \\
\text { membranes }\end{array}$ & 70 & 11 & 16 & Yes \\
\hline
\end{tabular}

$S A T=$ serum agglutination test. 
$1 \%$ of the general population and can be acceptable titres, but only for low-risk individuals.

Rates of seropositivity among high-risk occupations vary greatly in various countries. For example, $35.7 \%$ of abattoir workers in Saudi Arabia were seropositive in one study [8]. In Lebanon, $1.7 \%$ of persons in high risk occupations were seropositive based on SAT titre $\geq 1: 80$ [12]. In northern Jordan, the rate of seropositivity among high risk people was reported to be $8.2 \%$ [13]. Approximately $14 \%$ of asymptomatic, 'at risk' individuals screened in northern India were seropositivc for $B r u$ cella species [14]. These great differences may be due to cultural variations, especially poor hygiene practices employed by persons in high-risk occupations in various countries.

Seroprevalence rates among the gencral population also vary greatly in the Middle East $[6,8,10,11,15-20]$. In a similar study in southern Saudi Arabia, 4900 subjects were randomly selected in a house-tohouse survey. Investigations included interview, clinical examination and blood sampling for antibody titre determination by a microplate agglutination test. Standard tube agglutination and 2ME tests further analysed reactive sera. A significant proportion of the population $(19.2 \%)$ in the southern region had serological evidence of exposure to Brucella spp. antigen [11] A more recent study using SAT in various regions of Saudi Arabia [8] found the soroprevalence rate of brucellosis to be $20 \%$ in the northern region, $19 \%$ in the southern region and $11.6 \%$ in the western region. These rates of seropositivity were much higher than the rates reported from our study. Surprisingly, in the Republic of Yemen, a nearby country in the Arabian Peninsula, the rate of serologically positive samples was reported to range from $0 \%$ to $0.8 \%$ [19]. In Oman, the frequency of serologically positive sera in six locales ranged between $0 \%$ and $2 \%$ [20]. In Iraq, based on rose Bengal screening test and $\mathrm{SAT}$, approximately $6 \%$ of healthy randomly selected subjects were seropositive [6]. Data from Kuwait reported seroprevalence rales of approximately $12 \%$ [8]. Higher seroprevalence rates have been reported in sub-Saharan countries, with percentages of $18 \%$ in Uganda and $13 \%$ in Nigeria [ 8 ].

These data demonstrate the importance of regional variations of the disease in the endenic areas. However, high prevalence of lower titre seropositivity in this study was a significant marker for previous exposuic, alihough only one investigated risk factor (direct contact with placental membranes of domestic animals) was significantly related to SAT titres of $\geq 1: 80(P=$ 0.05 ). A history of such contact should be considered when interpreting SAT titres in endemic areas. There was also a strong relation between illiteracy and ignorance of routes of transmission and positive titres $\geq 1: 80$ (for $2 \mathrm{ME}, P=0.025$ and SAT, $P=$ 0.016 ).

In the absence of an efficient and effective method for cortrol of the disease, an educational programme, especially one regarding the routes of transmission, would be a cost-effective melhod for prevention and control. This is particularly so in this area as fresh white cheese, a popular food consumed daily by many people, is usually produced from unpasteurized sheep or goat milk.

In conclusion, a single litre of SAT $\geq 1: 80$ in the presence of $2 \mathrm{ME}$ titre $\geq 1: 20$ can be diagnostic in the general population in this area of the country. Nontetheless, serological studies in high-risk individuals should be interpreted cautiously and con- 
firmed only after a four-fold rising of titres or through bacteriological confirmation. Although the rising titre of antibodies to $\mathrm{Br}$ cella spp. is the most reliable serological method for accurate diagnosis, it is not always possible to postpone the diagnustic or therapeutic process.

\section{Acknowledgements}

The authors wish to thank Dr M. Amerhalil for submitting samples and questionnaires and B. Pourabas for assistance in performing the serological tests.

\section{References}

1. Young EJ. Brucella species. In: Mandell GL, Bennett JE, Dolin R, eds. Mandell, Douglas and Bennett's principles and practice of infectious diseases, vol. 2, 5th od. Edinburgh, Churchill Livingstone. 2000:2386-90.

2. Panahi M. Brucellosis. In: Azizi F, Janghorbani $M$, Hatami $H$, eds. Epidemiology and control of common disorders in Iran, 2nd ed. Teheran, Eshtiagh publication, 2000:533-41.

3. Karimi A et al. Active case finding of communicable diseases in the south of IsIamic Republic of Iran. Eastern Mediterranean health journal, 2000, 6:487-93.

4. Young EJ. Brucellosis In: Feigin RD, Cherry JD, eds. Textbook of pediatric infectious diseases, 4th ed. Philadelphia, WB Saunders Company, 1998:1417-21.

5. Sifuentes-Rincon $M$ et al. Detection and differentiation of the six Brucella species by polymerase chain reaction. Molecular medicine, 1997, 3:734-9.

6. Dabdoob WA, Abdulla ZA. A panel of eight tests in the serodiagnosis and immunological evaluation of acute brucellosis. Eastern Mediterranean health journal, 2000, 6:304-12.

7. Hurtado R. Brucellosis, new and old issues regarding diagnosis and management (http://www.mgh.harvard.edu/id/ images/brucellosis.pdf, Harvard education online, accessed 31 January 2001).

8. Al-Sekait MA. Seroepidemiological survey of brucellosis antibodies in Saudi
Arabia. Annals of Saudi medicine, 1999 , 10(3):210-22.

9. Gad El-Rab MO, Kambal AM. Evaluation of a Brucella enzyme immunoassay test (ELISA) in comparison with bacteriologic culture and agglutination. Journal of infectious diseases, $1998,36: 197-$ 201.

10. Dajani YH, Masoud AA, Barkat HF. Epidemiology and diagnosis of human brucellosis in Jordan. Journal of tropical medicine and hygiene, 1989, 92:20914.

11. Al-Ballaa SR. Epidemiology of human brucellosis in southern Saudi Arabia. Journal of tropical medicine and hygiene, 1995, 98:185-9.

12. Araj GF, Azzam RA. Seroprevalence of antibodies among persons in high-risk occupation in Lebanon. Epidemiology and infections, 1996, 117:281-8.

13. Abo-Shehada MN, Odeh JS, Abu-Essud $M$. Seroprevalence of brucellosis among high risk people in northern Jordan. International journal of epidemiology, 1996, 25:450-4.

14. Handa $R$ et al. Brucellosis in north India: results of a prospective study. Journal of communicable diseases, 1998, 30(2): 85-7.

15. Madkour M et al. Brucellosis in Saudi Arabia. Saudi medical journal. 1985 , 6:324-32.

16. Al-Ballaa SR et al. Seasonal variation of culture positivo brucollosis at a major 
teaching hospital. Annals of Saudi medicine, 1994, 14:12-5.

17. Mousa A et al. The nature of human brucellosis in Kuwait. Reviews of infectious diseases, 1998, 10:211-7.

18. Luhi AR et al. Iluman brucellosis In Kuwait. Quarterly journal of medicine, 1998, 66:39-44.
19. Al-Shamahy HA. The prevalence of Brucella antibodies in Yemen. Saudi medical joumal, 1997. 18:45-8.

20. Idris MA et al. Human bruceltosis in Dhofar, Sultanate of Oman. Journal of tropical medicine and hygiono, 1093, $96(1): 46-50$.

Regional Scminar on Prevention and Control of Zoonotic Diseases The WHO Reglonal Office for the Eastern Mediterranean in collaboration with the Minlstry of Health of Tunisia organized the abovementioned semirlar in Tunisia from 11 to 13 March 2003.

The purpose of the seminar was to:

- review the present status of prevention and control of major zoonotic diseases at the national level;

- identify prlority zoonoses by country; and

- upgrade the national strategles on prevention and control of zoonotic diseases.

Responsible officers for the national programmes on the prevention and control of zoonotic diseases frorr a number of ministries of health of the Region as well as veterinarlans Involved in, or collaborating with, the ministries of health participated in the seminar to. gether with nongovernmental organizatiurs and other united Mations organizations and concerned parties. 